\title{
Effectively managing intractable central hyperthermia in a stroke patient by bromocriptine: a case report
}

This article was published in the following Dove Press journal:

Neuropsychiatric Disease and Treatment

2 May 2013

Number of times this article has been viewed

\author{
Kuo-Wei Yu',* \\ Yu-Hui Huang 2,3 \\ Chien-Lin Lin ${ }^{1,4, *}$ \\ Chang-Zern Hong ${ }^{5}$ \\ Li-Wei Chou ${ }^{1,4}$ \\ 'Department of Physical Medicine \\ and Rehabilitation, China Medical \\ University Hospital, Taichung, Taiwan; \\ ${ }^{2}$ School of Medicine, Chung Shan \\ Medical University, Taichung, Taiwan; \\ ${ }^{3}$ Department of Physical Medicine \\ and Rehabilitation, Chung Shan \\ Medical University Hospital, Taichung, \\ Taiwan; ${ }^{4}$ School of Chinese Medicine, \\ College of Chinese Medicine, China \\ Medical University, Taichung, Taiwan; \\ ${ }^{5}$ Department of Physical Therapy, \\ Hungkuang University, Taichung, \\ Taiwan \\ *These authors contributed equally \\ to this work
}

\begin{abstract}
Central hyperthermia is characterized by a rapid onset, high temperature, marked temperature fluctuation, and poor response to antipyretics and antibiotics. Although poststroke central hyperthermia is common, prolonged instances are rare. We report a case of prolonged central fever after an intracranial hemorrhage. Before the accurate diagnosis and management of central fever, the patient underwent long-term antibiotic use that led to pseudomembranous colitis. Bromocriptine was used to treat the prolonged central hyperthermia, after which the fever did not exceed $39^{\circ} \mathrm{C}$. A week later, the body temperature baseline was reduced to $37^{\circ} \mathrm{C}$ and a low-grade fever with minor temperature fluctuation occurred only a few times. No fever occurred in the month following the treatment. After the fever subsided, the patient could undergo an aggressive rehabilitation program.
\end{abstract}

Keywords: bromocriptine, central hyperthermia, fever, stroke

\section{Introduction}

Fever is a frequent complication of stroke and is associated with worsened prognosis. ${ }^{1,2}$ Fever is likewise generally associated with infection because stroke patients are susceptible to various complications, such as aspiration pneumonia, urinary tract infection, or atelectasis. ${ }^{3,4}$ Most fevers that occur with stroke are caused by infections. Fevers without documented infection (probably that of central origin or "central hyperthermia") were determined in $33 \%$ of stroke patients in a prospective study. ${ }^{5}$ Fevers from a central origin and those caused by infection have completely different treatment strategies, and thus proper identification is important.

Central hyperthermia is characterized by a rapid onset, high temperature, marked temperature fluctuation, and higher mortality. ${ }^{5,6}$ Intracerebral hemorrhage, especially in the brainstem, is more predisposed in central fevers than in cerebral infarction. Most stroke patients with central fever had an increased temperature of $39^{\circ} \mathrm{C}$ within 1 day. ${ }^{7}$ However, central fever is not persistent, and abated within 96 hours in $90 \%$ of stroke patients. Central fever rarely occurs during the subacute stage of stroke. ${ }^{7}$ Antipyretics have no effect on central hyperthermia. ${ }^{8}$

In this paper, we present a case of a patient who suffered from prolonged central fever after an intracranial hemorrhage that involved cerebellar, putaminal, and brainstem hemorrhagic stroke. The fever was difficult to control until bromocriptine was administered.

Department of Physical Medicine and

Rehabilitation, China Medical University

Hospital, No 2 Yuh-Der Road,

Taichung, 404, Taiwan, ROC

Tel +886422052 I2I ext 238I

$\mathrm{Fax}+88642202604$ I

Email chouliwe@gmail.com

\section{Case report}

The 44-year-old male patient had good health before the onset of stroke. He did not have a past history of autoimmune disease or hepatitis, nor of recent travel. The patient was 
sent to the nearest emergency department of a community hospital because of dizziness and nausea with occasional vomiting. He was noted to be initially alert, but then his mental status rapidly declined.

The patient underwent rapid sequence intubation, and was transferred to the emergency department of the medical center. His blood pressure was 170/117 mmHg. Left pupil dilatation $(6 \mathrm{~mm})$ without light reflex was noted. The head computed tomography scan showed a large acute hematoma in the left cerebellum $(48 \mathrm{~mm} \times 46 \mathrm{~mm})$ ruptured into the fourth ventricle, which caused an intraventricular hemorrhage, and another acute hematoma in the pons and midbrain $(20 \mathrm{~mm} \times 20 \mathrm{~mm})$ (Figure 1A). An emergency bilateral suboccipital craniectomy was performed for hematoma removal. Intraventricular hemorrhage with external ventricular drain insertion was likewise performed (Figure 1B). One week later, the external ventricular drain was converted to the ventriculoperitoneal shunt. The patient underwent tracheostomy due to extubation failure. When the patient's condition stabilized, he was transferred to the regular ward. Consciousness improvement was noted using the Glasgow Coma Scale from E1 VtM1 to E4VtM5; however, intermittent fever had also been noted since his admission (Figure 2). Temperature was characterized by a spike fever with marked fluctuations ranging from $37^{\circ} \mathrm{C}$ to $41^{\circ} \mathrm{C}$. The neurosurgeon prescribed Unasyn ${ }^{\circledR}$ (ampicillin and sulbactam; Pfizer, Inc, New York, NY, USA) empirically for 2 weeks.

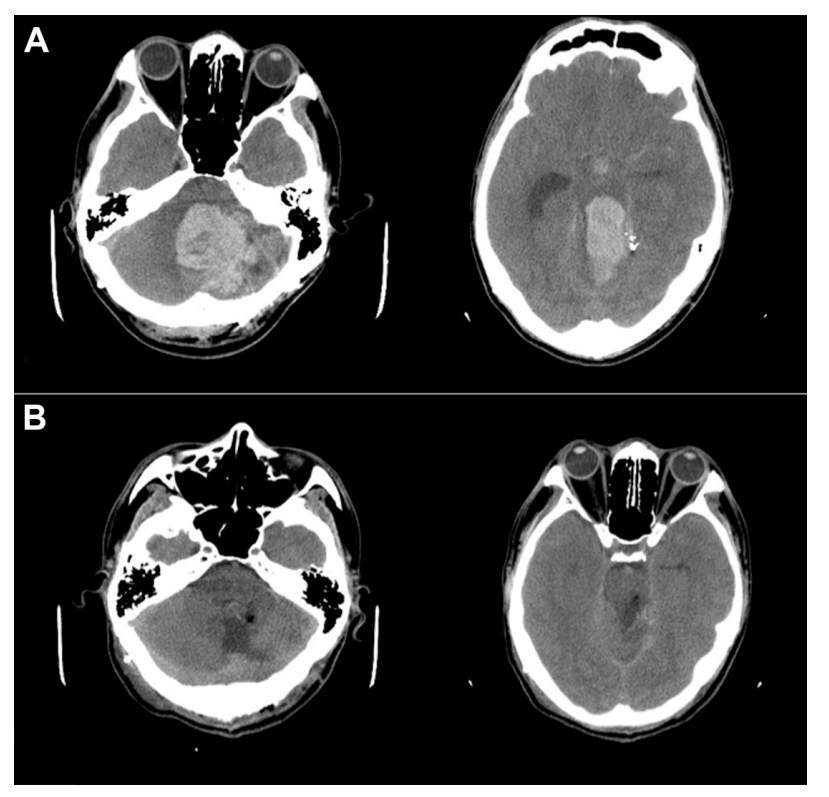

Figure I CT findings of the brain. (A) Left cerebellar hemorrhage and brainstem hemorrhage with IVH shown in the preoperational CT. (B) Encephalomalacia change in the left cerebellum and midbrain (30 days after the emergent operation). Abbreviations: $\mathrm{CT}$, computed tomography; IVH, intraventricular hemorrhage.
The antibiotics were changed to Tazocin ${ }^{\circledR}$ (piperacillin and tazobactam; Pfizer, Inc) because Pseudomonas was found in one set of the sputum culture. The antibiotics were then changed to Tienam ${ }^{\circledR}$ (imipenem and cilastatin; Merck and Co, Inc, Whitehouse Station, NJ, USA) because the intermittent high fever remained.

The fever persisted despite the full course of antibiotic treatment and normal white blood cell count, C-reactive protein, erythrocyte sedimentation rate, and negative blood cultures. The patient was then transferred to the rehabilitation ward. A complete fever workup was performed, but no definite infection source was found. The autoimmune profile blood test, including tests for antinuclear antibodies and rheumatoid factors, were negative. Tumor markers, including carcinoembryonic antigen, alpha-fetoprotein, and carbohydrate antigen 19-9, were likewise negative. Electroencephalograms showed no epileptic activity. Given the long-term use of antibiotics, we checked the stool toxin for Clostridium difficile and obtained a positive result. Pseudomembranous colitis was diagnosed and the patient received a full course of metronidazole. However, the fever with marked temperature fluctuations and poor response to antipyretics was still noted.

An inflammation scan was arranged to determine any infection or inflammation, which may have been the cause of the fluctuating high fever. No occult infections were revealed. Physical cooling, including sponging, using a wet towel, and removing clothing, were employed to reduce the temperature, but hyperthermia reoccurred when the physical cooling procedure ceased. Under the impression of central hyperthermia, bromocriptine $2.5 \mathrm{mg}$ /day was prescribed for 3 days and then increased to $5 \mathrm{mg} /$ day. In the following week, the fever did not exceed $39^{\circ} \mathrm{C}$. Another week later, the body temperature baseline was reduced to $37^{\circ} \mathrm{C}$, and low-grade fever with minor temperature fluctuations occurred only occasionally (Figure 2). The patient was discharged to the nursing home, and a follow-up 1 month later revealed no occurrence of fever.

Table 1 shows the fever pattern, impression/diagnosis, and management during the clinical course. After solving the fever problem, improved endurance and motivation were noted, and the patient was able to undergo more aggressive rehabilitation programs.

\section{Discussion}

Fever occurs in $23 \%$ of stroke patients, and a third of these were documented without infection. ${ }^{5}$ Central hyperthermia remains as an exclusion diagnosis. In these cases, even 


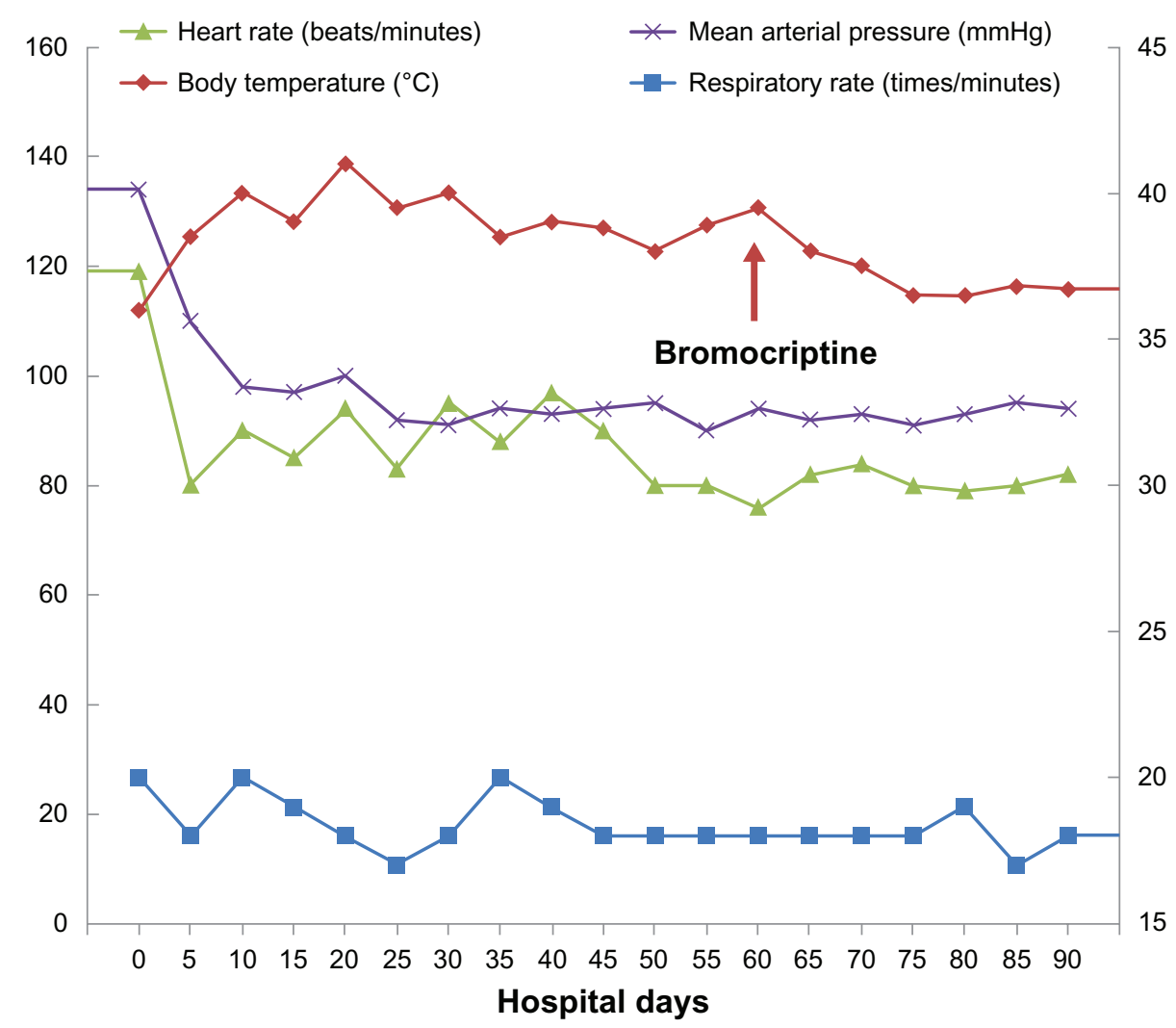

Figure 2 High fever with marked temperature fluctuation was noted during the clinical course.

Notes: Blood pressure, heart rate, and respiratory rate were within the normal range. The body temperature stabilized after the administration of bromocriptine.

negative culture results may not definitively rule out infection. Thus, not every febrile patient without documented infection has central hyperthermia.

Either the locations of stroke (supratentorial or infratentorial) and types of stroke (hemorrhagic or ischemic) may cause an elevation in body temperature on the first day of stroke. ${ }^{910}$ Although poststroke central hyperthermia is

Table I The fever pattern, impression/diagnosis, and management during the clinical course

\begin{tabular}{llll}
\hline $\begin{array}{l}\text { Days after } \\
\text { operation }\end{array}$ & $\begin{array}{l}\text { Fever } \\
\text { pattern }\end{array}$ & $\begin{array}{l}\text { Impression/ } \\
\text { diagnosis }\end{array}$ & Management \\
\hline $2-15$ & $\begin{array}{l}\text { Marked } \\
\text { fluctuation }\end{array}$ & Empirically & Unasyn* \\
16-31 & $\begin{array}{l}\text { Marked } \\
\text { fluctuation }\end{array}$ & $\begin{array}{l}\text { Sputum } \\
\text { Pseudomonas }\end{array}$ & Tazocin $^{+}$ \\
Marked & $\begin{array}{l}\text { No obvious } \\
\text { fever origin }\end{array}$ & Tienam $^{\#}$ \\
fluctuation & $\begin{array}{l}\text { Marked } \\
\text { fluctuation }\end{array}$ & $\begin{array}{l}\text { Pseudomembranous } \\
\text { colitis } \\
\text { Central }\end{array}$ & Metronidazole \\
$55-59$ & $\begin{array}{l}\text { Subsided } \\
\text { only in use } \\
\text { Subsided }\end{array}$ & $\begin{array}{l}\text { hentral } \\
\text { Central }\end{array}$ & Physical cooling \\
60 & hyperthermia & Bromocriptine \\
\hline
\end{tabular}

Notes: *Unasyn $^{\circledast}$ (ampicillin and sulbactam; Pfizer, Inc, New York, NY, USA) ${ }^{+}$Tazocin $^{\circledast}$ (piperacillin and tazobactam; Pfizer, Inc); ${ }^{\sharp}$ Tienam ${ }^{\circledast}$ (imipenem and cilastatin; Merck and Co, Inc, Whitehouse Station, NJ, USA). common, prolonged cases are rare. Central hyperthermia exceeding $39^{\circ} \mathrm{C}$ abated within 4 days for approximately $90 \%$ of patients. ${ }^{7}$

Differentiating central hyperthermia from an infection with fever is important because their treatments completely differ. In the present case, the diagnosis of central hyperthermia was delayed for several weeks, and the long-term use of antibiotics led to pseudomembranous colitis. Such a result was previously reported. ${ }^{11}$

Hyperthermia is detrimental to the recovery of an injured brain, and the duration of fever is associated with poor outcome. ${ }^{6,12}$ Therefore, the timely and accurate diagnosis of central hyperthermia is crucial and could prevent unnecessary antibiotic use. The characteristics of central hyperthermia include a rapid onset ( $76 \%$ of patients developed a fever of $39^{\circ} \mathrm{C}$ within 12 hours after the stroke), high temperature, marked temperature fluctuation, and poor response to antipyretics and antibiotics.

Central hyperthermia treatment is based on physical cooling. Pharmacological management of prolonged central hyperthermia is difficult to study due to high mortality and poor prognosis. Baclofen was successfully used to abolish the prolonged central hyperthermia in a case report. ${ }^{13}$ However, 
baclofen has side effects such as drowsiness, tiredness, and muscle weakness on the affected or unaffected limbs. ${ }^{14}$ These side effects may interfere with the rehabilitation program. Some medications have been reported to lower the body temperature after a traumatic brain injury by regulating the sympathetic activity. ${ }^{15}$ In another case report, a patient with traumatic brain injury and high fever of $40.5^{\circ} \mathrm{C}$ without documented infection received bromocriptine $(0.025 \mathrm{mg} / \mathrm{kg}$ twice daily and gradually increased to $0.05 \mathrm{mg} / \mathrm{kg}$ thrice daily). A comparison of the mean daily temperatures before and after the bromocriptine prescription revealed the significant lowering of body temperature $(P=0.003)$. The patient was slowly weaned from bromocriptine over the next 5 weeks. ${ }^{16}$

Bromocriptine is a dopamine agonist and acts at the level of the hypothalamus and corpus striatum. ${ }^{17}$ The hypothalamus regulates central autonomic activity and has numerous connections with other parts of the central nervous system. ${ }^{18}$ Hypothalamus dysfunction could lead to wide fluctuations in the core body temperature, ${ }^{19}$ and therefore bromocriptine could also be used to control central hyperthermia. ${ }^{16,17}$ Stroke could be associated with autonomic dysfunction, and hemorrhagic stroke is more common than ischemic stroke. ${ }^{20,21}$ Based on these reports, we selected bromocriptine to treat prolonged central hyperthermia without the side effects of baclofen, such as general weakness and lethargy. After the fever subsided, the patient could undergo an aggressive rehabilitation program.

\section{Conclusion}

This report describes a case of prolonged central hyperthermia managed with bromocriptine. Central hyperthermia should be considered as a possible diagnosis for a stroke patient with fever to prevent unnecessary antibiotic use. Bromocriptine may also be an effective treatment for central hyperthermia.

\section{Disclosure}

The authors report no conflicts of interest in this work. No commercial party having a direct financial interest in the results of the research supporting this article has or will confer a benefit upon the authors or upon any organization with which the authors are associated.

Neuropsychiatric Disease and Treatment

\section{Publish your work in this journal}

Neuropsychiatric Disease and Treatment is an international, peerreviewed journal of clinical therapeutics and pharmacology focusing on concise rapid reporting of clinical or pre-clinical studies on a range of neuropsychiatric and neurological disorders. This journal is indexed on PubMed Central, the 'PsycINFO' database and CAS.

\section{References}

1. Azzimondi G, Bassein L, Nonino F, et al. Fever in acute stroke worsens prognosis. A prospective study. Stroke. 1995;26(11):2040-2043.

2. Castillo J, Dávalos A, Marrugat J, Noya M. Timing for fever-related brain damage in acute ischemic stroke. Stroke. 1998;29(12):2455-2460.

3. Georgilis K, Plomaritoglou A, Dafni U, Bassiakos Y, Vemmos K. Aetiology of fever in patients with acute stroke. J Intern Med. 1999; 246(2):203-209.

4. Roth EJ, Lovell L, Harvey RL, Heinemann AW, Semik P, Diaz S. Incidence of and risk factors for medical complications during stroke rehabilitation. Stroke. 2001;32(2):523-529.

5. Morales-Ortiz A, Jiménez-Pascual M, Pérez-Vicente JA, MongeArguiles A, Bautista-Prados J. Fever of central origin during stroke. Rev Neurol. 2001;32(12):1111-1114.

6. Schwarz S, Häfner K, Aschoff A, Schwab S. Incidence and prognostic significance of fever following intracerebral hemorrhage. Neurology. 2000;54(2):354-361.

7. Sung CY, Lee TH, Chu NS. Central hyperthermia in acute stroke. Eur Neurol. 2009;62(2):86-92.

8. Shibata M. Hyperthermia in brain hemorrhage. Med Hypotheses. 1998; 50(3):185-190.

9. Boysen $\mathrm{G}$, Christensen H. Stroke severity determines body temperature in acute stroke. Stroke. 2001;32(2):413-417.

10. Leira R, Rodríguez-Yáñez M, Castellanos M, et al. Hyperthermia is a surrogate marker of inflammation-mediated cause of brain damage in acute ischaemic stroke. J Intern Med. 2006;260(4):343-349.

11. Moudgal V, Sobel JD. Clostridium difficile colitis: a review. Hosp Pract (Minneap). 2012;40(1):139-148.

12. Reith J, Jørgensen HS, Pedersen PM, et al. Body temperature in acute stroke: relation to stroke severity, infarct size, mortality, and outcome. Lancet. 1996;347(8999):422-425.

13. Huang YS, Hsiao MC, Lee M, Huang YC, Lee JD. Baclofen successfully abolished prolonged central hyperthermia in a patient with basilar artery occlusion. Acta Neurol Taiwan. 2009;18(2):118-122.

14. Hulme A, et al. Baclofen in the elderly stroke patient its side-effects and pharmacokinetics. Eur J Clin Pharmacol. 1985;29(4):467-469.

15. Lemke DM. Sympathetic storming after severe traumatic brain injury. Crit Care Nurse. 2007;27(1):30-37; quiz 38.

16. Russo, RN, O'Flaherty S. Bromocriptine for the management of autonomic dysfunction after severe traumatic brain injury. J Paediatr Child Health. 2000;36(3):283-285.

17. Kang SH, Kim MJ, Shin IY, Park DW, Sohn JW, Yoon YK. Bromocriptine for control of hyperthermia in a patient with mixed autonomic hyperactivity after neurosurgery: a case report. J Korean Med Sci. 2012;27(8):965-968.

18. Carmel PW. Vegetative dysfunctions of the hypothalamus. Acta Neurochir (Wien). 1985;75(1-4):113-121.

19. Ordu Gokkaya NK, Daylan Aras M, Oken O, Koseoglu F. Fever during post-acute rehabilitation in patients with brain injury. J Rehabil Med. 2005;37(2):123-125.

20. Xiong L, Leung HH, Chen XY, et al. Comprehensive assessment for autonomic dysfunction in different phases after ischemic stroke. Int J Stroke. Epub July 3, 2012.

21. Perkes I, Baguley IJ, Nott MT, Menon DK. A review of paroxysmal sympathetic hyperactivity after acquired brain injury. Ann Neurol. 2010;68(2):126-135. a very quick and fair peer-review system, which is all easy to use. Visit http://www.dovepress.com/testimonials.php to read real quotes from published authors. 